\title{
BLOCKCHAIN TECHNOLOGY AND NFT'S: A REVIEW IN MUSIC INDUSTRY
}

\author{
DOI: 10.17261/Pressacademia.2021.1454 \\ JMML- V.8-ISS.3-2021(2), p.154-163
}

\section{Cagla Gul Senkardes}

Istanbul Bilgi University, Faculty of Engineering and Natural Sciences, Istanbul, Turkey. caglasenkardes@gmail.com, ORCID: 0000-0002-3109-3268

\begin{tabular}{l}
\hline Date Received: July 4, $2021 \quad$ Date Accepted: September 19, $2021 \quad$ open OAaccEss $\quad$ (cc)BY \\
\hline To cite this document \\
Gul Senkardes, C., (2021). Blockchain technology and NFT's: a review in music industry. Journal of Management, Marketing and Logistics \\
(JMML), 8(3), 154-163 \\
Permanent link to this document: http://doi.org/10.17261/Pressacademia.2021.1454 \\
Copyright: Published by PressAcademia and limited licensed re-use rights only. \\
\hline
\end{tabular}

\section{ABSTRACT}

Purpose- Blockchain technology, which is one of the newest technologies, offers an unchangeable, transparent, and reliable data management infrastructure. Crypto assets, the use of which is rapidly becoming widespread with blockchain technology, are changing the dynamics of many traditional industries. NFTs, one of the crypto asset types, have started to become widespread in the art industry very quickly, especially as of 2020. A global application in the music industry regarding blockchain technology and NFT applications, which has the potential to cause a significant transformation at the intersection of the art industry with digital technologies, was first implemented in 2021. In this article, a literature review is made on the advantages and disadvantages of the use of NFTs in the music industry, and a discussion is presented on the first application. With this research article, it is aimed to contribute to the academic literature in this interdisciplinary field, which is at the intersection of technology, art and marketing disciplines by discussing the future potential of NFT applications.

Methodology- In the article, secondary source scanning and sample usage were examined as a method. Secondary sources used includes books, articles, and online publications on blockchain technology and NFTs. A first and global NFT project applied in the music industry is examined and discussed with literature review findings.

Findings- NFT applications in the music industry have advantages in the areas of proof of uniqueness, copyrights, new business models, digital integration, and security. The fact that NFTs depend on the blockchain infrastructure they are developed, privacy issues, difficulties in user experience, and lack of legal regulations are the findings defined as disadvantages of NFTs.

Conclusion- The use of NFT applications in the music industry and related products and services, which do not have many resources in the academic literature, has been examined through publications and internet resources, and a sample application. While there are innovations and benefits that come with the implementation of NFTs, there are also obstacles to the implementation of these applications. This article presents a discussion of the advantages and disadvantages of using NFTs in the music industry and contributes to the Turkish academic literature. The results of the widespread use of NFTs, which have the potential to provide significant advantages in the music industry, should be followed and supported by research.

Keywords: Blockchain technology, bitcoin, NFT, art, music industry.

JEL Codes: L86, Q55, Z11

\section{BLOKZINCIR TEKNOLOJISI VE NFT'LER: MÜZIK ENDÜSTRISi ÜZERINE BIR INCELEME}

\section{ÖZET}

Amaç - En yeni teknolojilerden biri olan blokzincir teknolojisi değiştirilemez, şeffaf, ve güvenilir veri yönetimi altyapısı sunmaktadır. Blokzincir teknolojisi ile kullanımı hızla yaygınlaşan kripto varlıklar geleneksel sektörlerde dinamikleri hızla değiştirmektedir. Kripto varlık çeşitlerinden olan NFT'ler, özellikle 2020 yılı itibarı ile çok hızlı bir şekilde sanat endüstrisinde yaygınlaşmaya başlamıştır. Sanat endüstrisinin dijital teknolojilerle kesişiminde önemli bir dönüşüme neden olma potansiyeline sahip olan blokzincir teknolojisi ve NFT uygulamaları ile ilgili müzik endüstrisinde küresel çaplı bir uygulama ilk kez 2021 yılında hayata geçmiştir. Bu makalede NFT’lerin müzik endüstrisinde kullanımının avantaj ve dezavantajları üzerine literatür taraması yapılarak, hayata geçirilen ilk uygulama üzerinden bir tartışma sunulmaktadır. Bu araştırma makalesi ile NFT uygulamalarının gelecek potansiyelinin tartışılarak teknoloji, sanat ve pazarlama bilim dallarının kesişiminde olan disiplinler arası bu alanda akademik literature katkı sağlamak amaçlanmaktadır.

Metodoloji - Makalede yöntem olarak ikincil kaynak taraması ve örnek kullanım şekli incelemesi yapılmıştır. Kullanılan ikincil kaynaklar; blokzincir teknolojisi ve NFT konularındaki kitap, makale ve çevrimiçi yayınları içermektedir. Müzik endüstrisinde uygulanan ilk ve küresel bir NFT projesi incelenerek, literatür tarama bulguları ile tartışılmıştır.

Bulgular- Müzik endüstrisinde NFT uygulamalarının eserlerin benzersizlik ispatı, telif hakları, yeni iş modelleri, dijital entegrasyon, ve güvenlik alanlarında avantajları bulunmaktadır. NFT'lerin blokzincir altyapısına bağlı olması, gizlilik sorunları, kulanıcı deneyimindeki zorluklar, ve yasal düzenlemeler olmaması NFT'lerin dezavantajları olarak tanımlanan bulgulardır.

Sonuç- İncelenen yayınlar ve örnek uygulama ile akademik alanyazında henüz fazla kaynak bulunmayan NFT uygulamalarının müzik endüstrisinde, ve bağlantılı ürün ve hizmetlerde kullanımı incelenmiştir. NFT'lerin uygulanması ile ortaya çıkan yenilikler ve faydalar olmakla birlikte, bu uygulamaların hayata geçirilmesinin önünde engeller de bulunmaktadır. Bu makale, müzik endüstrisinde NFT kullanmanın avantaj ve dezavantajlarının bir tartışmasını sunmakta ve Türkçe akademik alanyazına katkı sağlamaktadır. Müzik endüstrisinde önemli avantajlar sağlama potansiyeli olan NFT’lerin yaygınlaşmasının üreteceği sonuçlar takip edilerek araştırmalarla desteklenmelidir.

Anahtar Kelimeler: Blokzincir teknolojisi, bitcoin, NFT, sanat, müzik endüstrisi.

JEL Kodları: L86, Q55, Z11 


\section{GíRiş}

İçinde bulunduğumuz ve Endüstri 4.0 adı verilen dönem, 1800’lü yıllarda başlayan sanayi devrimlerinin dördüncüsü ile başlamıştır. Dördüncü sanayi devrimi, bir çok farklı dijital teknoloji ile beslenen sistemlerin, fiziksel sistemler ile bir arada kullanımı ile verimliliğin ve üretimin arttığı dönemdir. Bu dönem özellikle dijital dönüşümün ana iş süreçlerindeki değişimi tetiklemesi ile temelde akıllı ve bağlantılı ürünler odağında gerçekleşmektedir. Teknoloji destekli otomatize edilmiş sistemler ve cihazlar birbirleri ile internet üzerinden veri alışverişi yaparak iletişim kurabilmektedir. Bu iletişimin çıktısı olarak, sanayi üretiminin yanı sıra bu dönem, yeni gelişen dijital sistemler ve mecralar ile birlikte dijital dünyada gerçekleşen üretimi de hızlandırmıştır. Bu durum çoğu endüstrinin dinamiklerini dönüştürürken, ekonominin bu yeni alanlarda gelişmesine imkan sağlamıştır. Özellikle 20. yüzyılda kaydedilen büyük ölçekli ve tarihi ekonomik büyümenin temel sebepleri arasında teknik ve teknolojik gelişmeler ile üretimde artan verimlilik yer almaktadır. (Martine, Alves, 2015) Yeni teknolojiler ekonomik, sosyal, ve ekonomik dönüşümü mümkün kılmıştır. (Cohen, Amorós, Lundyd, 2017) Veri bilimi gibi yeni endüstrilerin yaratılmasının, platform tabanlı iş modellerinin gelişmesinin, dijital içerik üretimi endüstrisinin büyümesinin, ve daha birçok yeni iş kolunun ekonomiye dahil olmasının gerçekleştiği Endüstri 4.0 dönemi tarihi seviyede ekonomik büyümeyi de beraberinde getirmiştir. Toplumun bilgi iletişim teknolojileri ile etkileşiminin artması ile birlikte sanayi toplumundan bilgi toplumuna geçiş de bu dönemde gerçekleşmiştir. Bilgi toplumu, bilgiyi hem üreten hem de ekonomiden kültüre hemen her alanda kullanan yeni bir toplum tipidir. Bilgi toplumunda başlıca unsur olan bilginin kendisi, küreselleşme, ve dijital teknolojiler ile beraber ürüne dönüşmektedir. Post modern ekonomide alınıp satılabilen bir ürün haline gelen bilginin tanımında veri önemli bir yer tutmaktadır. Özellikle veri üretimi ve işlenmesinin önemli bir parçası olduğu dijital sanat da bilgi üretimi bağlamında bu dönem tartışılan yeni kavramları ortaya çıkarmaktadır. Veriye dayalı dijital sanat üretimi ve bağlantılı platformlar için verinin güvenilir bir şekilde saklanması, işlenmesi, ve transfer edilmesi kritik önem taşıyan bir konu hale gelmiştir. Geleneksel sanat endüstrisinde sahipliğin aracılara bağımlı el değiştirdiği yapıya alternatif olarak ortaya çıkan ve aracısız bir şekilde sahipliğin el değiştirmesine imkan veren blokzincir teknolojisi, sanat endüstrisine kapsayıcı ve küresel yeni bir vizyon sunmaktadır. Blokzincir teknolojisi bir yandan sanata erişimi liberal bir yaklaşım ile demokratikleştirirken, bir yandan da sanat eserlerinin orjinalliğinin kayıt altına alınabilmesine imkan vermektedir. Sanat ve bağlantılı ürünlere erişimi kolaylaştıran blokzincir teknolojisinin ürünlerinden olan ve NFT (Non-Fungible Token) olarak anılan benzersiz kripto paralar 2017 yılından bu yana kullanılmaktadır. Bu makalede, 2020 yılı itibarı ile sanat endüstrisinde kullanımı yaygınlaşmaya başlayan NFT'lerin müzik endüstrisinde kullanımının avantajları ve dezavantajları tartışılmaktadır.

\section{LITERATÜR TARAMASI}

\subsection{Blokzincir Teknolojisi}

Blokzincir teknolojisi, dördüncü sanayi devrimi için tıpkı internetin üçüncü sanayi devrimi için olduğu kadar önemli bir teknolojidir. En temel düzeyinde yeni, merkeziyetsiz ve küresel olarak yönetişimdeki birçok mevcut süreci dönüştürebilecek bir altyapı sunan blokzincir teknolojisinin, bilgi toplumu üzerindeki potansiyel etkisinin genişliği ve derinliği hakkında yaygın tartışmalar mevcuttur. (Tapscott, Tapscott, 2016; Iansiti, Lakhani, 2017) Blokzincir, verilerin internet üzerinden zaman damgalı olarak, dağıtık bir yapıda, şifrelenerek, değiştirilemez bir şekilde kaydedilmesine ve transfer edilmesine imkan veren, güvenli, şeffaf bir dijital işlem defteri sağlayan teknolojidir. Blokzincir kelimesi ilk kez Satoshi Nakamoto isimli bir yazarın 2008 yılında yayınladığı "Bitcoin: A Peer-to-Peer Electronic Cash System" adlı makalesi üzerine başlayan tartışmalarda kullanılmıştır. Makalede tariflenen sistemde transfer edilen Bitcoin, kripto para birimi olarak blokzincir altyapısı üzerinde, geleneksel finans

sisteminden ve hükümetlerden bağımsız olarak alternatif bir sistem ve ödeme aracı olarak tasarlanmıştır. Yine makalede eşler arasında transfer gerçekleşmesini mümkün kılan elektronik para sisteminin altyapısı açıklanmış ve bu sistemi mümkün kılan teknoloji altyapısı blokzincir olarak tariflenmiştir. Nakamoto' ya (2008) göre blokzincir altyapısında gerçekleşen her işlem ile ilgili bilgi bu işlemleri çözen, kontrol eden ve onaylayan düğüm adı verilen katılımcılar tarafından dağıtık bir veri yönetim sistemi halinde kaydedilir ve paylaşılır. Blokzincir birçok araştırmacı tarafından, gerçekleşen işlemlerin güvenirliğinin ağdaki katılımcılar tarafından doğrulandığı güvenilir, şeffaf, ve değiştirilemez bir veri yapısı ve veri yönetim aracı olarak tanımlanmıştır. (Zheng ve diğerleri, 2017; Glase, 2017; Halpin, Piekarska, 2017) Bu özelliği ile blokzincir kullanıcılar için merkezi olmayan dağıtık veri yapısı sayesinde güvenliğin temelini oluşturmaktadır. (Narayanan, Clark, 2017)

Internet teknolojisi ile birlikte küresel ölçekte iletişim ve etkileşim kolay hale gelmiş ve akıllı telefonlar, nesnelerin interneti gibi teknolojiler hızla yaygınlaşmaya başlamıştır. "Sanayi toplumunun alt yapısı limanlar, demiryolları, karayolları, havaalanları gibi taşımacılık ağları iken; bilgi toplumunun alt yapısı; kablo, geniş bant, dijital televizyon, optik fiber ağ, fax, e-mail, ISDN olmak üzere iletişim ağlarından oluşmaktadır." (Yeşilorman, Koç, 2014) Bu tanım ile bilgi toplumunun üretim araçları arasına veri ve veri yönetişim araçları dahil edilmektedir. Illetişim bilimci Marshall McLuhan (1964:13) "bilgiyi taşıyan araç mesajdır" teorisi ile verilerin iletildiği araca göre değişiklik göstereceği konusunu tartışmaktadır. Bilgi ve iletişim teknolojilerinde araçların bilgiyi şekillendireceği görüşü çift taraflı bir etkileşime vurgu yapmaktadır. Günümüzde internette, kendi sunucusunu çalıştıran tekil 
kişiler tarafından yönetilen bilgiler kullanılmaktadır. Blokzincir teknolojisi ise kullanıcılara kendi verilerinin, kimliğinin ve dijital varlıklarının sahibi olabilme imkanını sağlaması ile hızla tercih edilmeye başlamış olan yenilikçi ve liberal bir veri yönetim sistemidir. Blokzincir teknolojisi bir verinin kişiler yada farklı partiler arasında herhangi bir aracıya gerek duyulmadan doğrudan iletimini sağlayabilen bir altyapı sunabilmektedir. Teknolojinin sunduğu en son veri iletim aracı olan bu teknoloji ile bilginin ve dolayısı ile verinin değiştirilmeden iletimi sağlanabilmektedir. Bu teknolojiyi altyapı olarak kullanan bir çok uygulama ile finanstan, lojistiğe ve sanata kadar bir çok farklı sektörde ürün ve hizmetler sunulmaya başlanmıştır. Blokzincir tabanlı ürün ve hizmetler kullanıldıkları sektörlerde yenilikçi bir bakış açısı sunarak önemli etkiler yaratmaya başlamıştır.

\subsection{Yeni Bir Kripto Para Çeşidi: NFT}

Bitcoin protokolü ile hayatımıza giren ve eşler arası, aracısız para transferi yapılmasını mümkün kılan blokzincir teknolojisi, 2015 yılında kullanıma sunulan Ethereum protokolü ile yeni bir vizyon kazanmıştır. Ethereum blokzincir protokolü, kripto para araştırmacısı ve yazılımcısı Vitalik Buterin ile ekibi tarafından geliştirilmiştir. 27.Kasım.2013 tarihinde whitepaper adı verilen teknik bilgi dokümanı yayınlanan Ethereum protokolü, 30.Temmuz.2015 tarihinde 'Genesis' adı verilen ilk blok üretiminin yapılması ile hayata geçmiştir. Ethereum ile tanıtılan 'Akıllı Sözleşme' adı verilen yazılımlar ile, blokzincir teknolojisinin kullanım alanları para transferinin ötesinde genişleme imkanı bulmuştur. 2014 yılında Ethereum blokzincirinin geliştiricileri tarafındanyapılmış olan ilk açıklama ile Ethereum blokzinciri "kullanıcıların gelişmiş işlem türlerini, akıllı sözleşmeleri, ve merkezi olmayan uygulamaları blokzincire kodlamasını sağlamak için tasarlanmış olan, yeni nesil dağıtılmış bir kriptografik defter" olarak tanımlanmıştır. (Waybackmachine, 2014) Ethereum blokzinciri, Bitcoin'den farklı olarak kullanıcılarının farklı sözleşmeler oluşturmasına ve para transferi dışında çok farklı verilerin sisteme kaydedilerek kendi bellirleyecekleri kurallara göre işlem yapmasına imkan sağlayan bir programlama dili içerir. Kurucusu Boterin'in sihirli bir bilgisayar olarak tanımladığı Ethereum, programlanabilir blokzincir sunmayı hedeflemiş ve bu özelliği ile Bitcoin'den farklılaşmıştır.

Ethereum, temelde Bitcoin gibi aracısız işlem yapılabilmesini sağlamasının ötesinde çok farklı işlemler ve uygulamalar için kullanılabiliyor olması nedeni ile blokzincir 2.0'a geçiş olarak anılmaktadır. Ethereum blokzinciri açık ve izinsiz bir altyapıya sahiptir ve dünyada en fazla sayıda geliştirici tarafından üzerinde akıllı sözleşmeler ile uygulamalar geliştirilmektedir. (Beck et al., 2016) Ethereum'u farklılaştıran akıllı sözleşmeler, Ethereum blokzincirinde belirli bir adreste bulunan bir kod ve veri durumu bilgisi şeklinde çalışan bir programdır. Akıllı sözleşmeler, her bir sözleşmeye özel programlanmış bilgilere uygun şekilde çalışırlar ve Ethereum ağı üzerinde hiçbir kullanıcı tarafından yönetilmelerine gerek olmadan çalışırlar. Ethereum (2021) tarafından yayınlanan bilgilere göre "Akıllı sözleşmeler, normal bir sözleşme gibi kurallar tanımlayabilir ve bunları kod aracıllı̆ıyla otomatik olarak uygulayabilir." Sahip olduğu akıllı sözleşme yazılımları ile farklı kripto varlıkların geliştirilmesine ve transfer edilmesine imkan veren Ethereum blokzinciri ERC-721 (Ethereum Request for Comments 721) standardı, benzersiz olan tokenların üretimine imkan vermiştir. William Entriken, Dieter Shirley, Jacob Evans, Nastassia Sachs tarafından Ocak 2018'de önerilen ERC721standardı, benzersiz olan tokenların yönetilmesi, sahiplenilmesi, ve alınıp satılmasına izin vermek için akıllı bir sözleşmenin uygulaması gereken minimum bir arayüzü tanımlamaktadır. (ERC721, 2021) Bu arayüz ERC-721 token meta verileri için bir standart zorunlu kılmamakta veya token içeriğine ek işlevler eklenmesini kısıtlamamaktadır. ERC-721 standardını kullanan uygulamalar, birçok şeyin sahipliğini anonim hesaplara atayarak kaydedebilmektedir.

Varlıkların tokenize edilerek benzersiz bir şekilde kimliklendirilmesi veya sahipliğinin benzersiz şekilde kanıtlanabilmesine imkan veren, Non-Fungible Token (NFT) adı verilen ve biricik veya eşsiz tokenlar olarak tanımlanabilecek olan NFT'ler, Ethereum

blokzinciri üzerinde geliştirilmiş olan ERC 721 standına bağlı olarak üretilmektedir. NFT'ler, blokzincir üzerinde geliştirilen bir çeşit kripto para türüdür. Kripto paralar birçok farklı yöntemlerle ve farklı özelliklerine göre sınıflandırılabilmektedir. Kripto paralar arasında kendi blokzinciri üzerinde çalışan veya herhangi bir blokzincir üzerine üretilmiş olmalarına göre, hizmet amaçlarına göre, iş ispatı veya hisse ispatı yöntemine göre çalışan blokzincir altyapısına göre farklı kavramsal yaklaşımlar üreterek sınıflandırmalar yapmak mümkündür. NFT'ler ise tüm bu sınıflandırmalardan farklı bir özelliğe sahiptir. NFT'ler benzersizdir. NFT'ler diğer kripto paralar gibi takas edilemezler. Takas edilemez tanımı ekonomik bir terim olup, bir mobilya, bir beste veya bilgisayarınız gibi kendilerine has ve benzersiz özellikleri olan varlıkları tanımlamak için kullanılır. Takas edilebilir varlıklar benzersiz özelliklerinden ziyade maddi değerleri üzerinden tanımlanır. Bir Türk Lirası'nı başka herhangi 1 Türk Lirası ile veya 1 Bitcoin'i o anki maddi değerine eş Türk Lirası ile takas edilebilir. Fakat bir NFT başka herhangi bir NFT ile takas edilemez. Benzer şekilde bir önceki paragrafta detaylı değinilmiş olan Ethereum blokzincirinin kripto parası Ether'dir ve elinizdeki bir Ether'i kullandığınız işlem platformunda herhangi bir farklı kripto varlık ile piyasa fiyatı üzerinden takas edebilirsiniz. Yani 1 Ether herhangi başka 1 Ether'den farklı değildir. Fakat her bir NFT, bir varlık veya kişi ile ilgili bilgileri benzersiz bir şekilde temsil eder ve biricik özelliklere sahiptir. Diğer kripto paralardan farklı olarak NFT'ler para tutmak yerine benzersiz olan bir sanat eseri, bilet, varlık, hizmet yada belgeyi temsil edebilmektedir. NFT'lerin içeriğinden benzersiz bir koleksiyon ürünü, dijital bir benzersiz varlık veya tokenize edilmiş bir benzersiz fiziksel varlık ile ilgili kayıt bulunabilir. NFT'lerin değeri değişebilmektedir ve bu içeriğindeki değere bağlıdır. Her bir NFT, herhangi bir varlığı veya kişiyi benzersiz bir şekilde temsil etmek üzere üretilmiştir. Aynı şekilde benzersiz varlıkların sahipliğini de temsil ederler. Varolan bir NFT içeriğini kopyalama ve yapıştırma yaparak NFT olarak yeniden 
üretmek bu standarda bağlı olarak mümkün değildir. Bu özelliği nedeni ile NFT'ler koleksiyon ürünleri, sanat eserleri, numaralı gösteri biletleri veya özel tasarım ürünlerin yer aldığı platformlarda rahatlıkla kullanılabilmektedirler.

Dijitalleşmenin ivmelenerek arttığı ve birçok varlık, bilgi ve verinin internet üzerinde yaratılıp işlendiği günümüzde, dijital ortamda varlıklar için nadirlik ve sahiplik kolaylıkla çoğaltılabilme imkanından dolayı yönetilmesi zor konular haline gelmiştir. NFT'ler bu noktada önemli bir soruna çözüm sunmaktadır. Dijital bir ürün kopyalanarak çoğaltılabilir fakat NFT olarak blokzincir üzerine kaydedilmiş bir dijital varlık, kendisine ait benzersiz ve çoğaltılamayacak bir belirteç ile kimliklendirildiğinden bu bilgi kopyalanamaz. Her bir NFT'nin bu kimliği ile kolaylıkla kanıtlanabilir bir şekilde sahipliği de aynı şekilde korunabilmekte ve ispatlanabilmektedir. Sahibi tarafından kolaylıkla satılabilen NFT'ler, bu işlem için aracı gerektirmezler. Bir NFT ürettiğinde, blokzincir üzerinde onun kimin tarafından üretildiği değiştirilemez bir şekilde kayıt altına alınmaktadır. Telif hakkı konusunda varlık sahibinin haklarına NFT'ler ile çok güçlü koruma sağlanmaktadır. Blokzincir üzerinde zaman damgalı olarak kayıt altına alınan üretim ve sahiplik bilgileri ile telif hakları kolayca korunabilmekte ve ispatlanabilmektedir. Buna ilave olarak akıllı sözleşmeye yazılacak bilgilere göre NFT her satıldığında üreticisine otomatik ve şeffaf bir şekilde belirlenen kurallara göre telif hakkı payı ödemesi yapılabilmektedir. Bu işlem için de hiçbir aracıya ihtiyaç duyulmaz. Herhangi bir kripto para gibi NFT'ler de transfer edebilmekte ve satabilmektedir. Bir NFT satın aldığında artık sahipliğinin satın alan kişiye ait olduğu blokzincir üzerinde şeffaf bir şekilde kayıt altına alınır. Bir NFT'nin nadirliği veya kaç adet benzer varlıktan var olabileceği de üreticisinin isteğine bağlı olmaktadır. Yani bir sanat eserinden sadece 1 adet NFT üretmek veya daha fazla adette üretmek aynı kolaylıktadır ve buna sadece üreticisi tarafından karar verilir. Aynen her bir fiziksel ürün üzerinde bulunan barkod gibi, her bir dijital eseri temsil eden NFT için üretilmiş benzersiz bir kimlik bulunmaktadır. Ve tüm nadirliğe ait bilgiler herkese açık ve şeffaf bir şekilde blokzincir üzerinde yer almaktadır.

NFT'lerin piyasa hacmi 2020 yılından bu yana hızla büyümektedir ve 2021 yılı Haziran ayında toplam var olan 10.410 adet kripto para içerisinde 233 adede ulaşan NFT protokolünün toplam pazar değeri 20 milyar Amerikan Dolarının üzerindedir. (Coin Market Cap, 2021) İlk kez Axion Ez tarafından Cryptokitties projesinde kullanılmaya başlayan ERC-721 standardı, bugün kripto ekosisteminde birçok farklı sektörde hayata geçen projelerde kullanılmaktadır. (ERC721, 2021) Ethereum blokzinciri üzerinde geliştirilmiş olan Cryptokitties isimli oyun içerisinde üretilen ve tanesi 170 bin Amerikan Doları bedel ile satılmış olan dijital varlıklar oyun endüstrisinde üretilmiş ilk NFT örnekleridir. (The Verge, 2021; The NewYork Times, 2021) Şimdiye kadar hayata geçirilen en başarılı NFT uygulamalarından olan Cryptokitties, dijital ortamda üretilen kedilerin takas edilmesine ve satılmasına odaklı bir oyundur. Milyon dolarlara ulaşan satış gelirleri ve satılan kedilerin mülkiyeti temel olarak ERC-721 kullanılarak blokzincire kaydedilmiştir. Bugüne kadar en yüksek fiyata satılmış NFT'ler arasında Twitter'ın kurucusunun 3 milyon Amerikan Doları bedel ile sattığı tweet mesajı ve Beeple tarafından üretilmiş olan 69 milyon Amerikan Doları bedel ile satılmış olan bir eser bulunmaktadır. (The Verge, 2021) Bugün birçok farklı blokzincir protokolü ve Nifty Gateway, OpenSea, Rarible gibi NFT'lerin alım satım işlemlerinin yapılabildiği birçok farklı pazar yeri bulunmaktadır. En yüksek hacimli NFT koleksiyonu olan NBA Topshot'ta 397.430 adet koleksiyoner bulunmakta ve hacim 596 milyon Amerikan Doları iken ikinci sıradaki en büyük koleksiyon olan CryptoPunks'ta işlem yapan 3210 kişi toplam 356 milyon Amerikan Doları tutarında işlem yapmıştır. (The Verge, 2021)

\section{3. ÇALIŞMANIN YÖNTEMI}

Bu çalışmada yöntem olarak ikincil kaynak taraması ve örnek kullanım şekli incelemesi kullanılmıştır. Müzik endüstrisinde uygulanan ilk ve küresel bir NFT projesi bu bölümde incelenerek, ikincil kaynak literatür tarama bulguları ile makalenin 4. Bölümünde avantajları ve dezavantaları üzerinden tartışılıştır. Proje incelemesi için veriler çevrimiçi yayınlar ve haber sitelerinden yapılan araştırmalardan derlenmiştir. Tartışma için kullanılan ikincil kaynaklar blokzincir teknolojisi ve NFT konularındaki makale ve çevrimiçi yayınları içermektedir.

Sanat sektöründe hızla yaygınlaşmaya başlayan NFT uygulamaları, müzik endüstrisinde ilk geniş kapsamlı uygulamaya 5 . Mart.2021 tarihinde Kings of Leon (KOL) müzik grubu 'When You See Yourself' adlı yeni albümünü, NFT olarak yayınlaması ile konu olmuştur. Müzik endüstrisinde NFT uygulama örneği olarak bu proje seçilmiştir. KOL'un bu albümü, müzik albümlerin yayınlandığı farklı müzik platformlarında da yayınlanmıştır fakat albümün NFT uygulaması ile üretilen versiyonu özel avantajlara sahip tek ürün olma özelliğini taşımaktadır. Albümün belirli bir adette NFT olarak satışa sunulduğu bu projede, NFT albümlerin satışı sadece iki hafta sürmüştür ve daha fazla üretimi yapılmayacaktır. Çoğaltılma imkanı olmayan KOL'in bu NFT albümü artık sadece takas edilebilir özel bir koleksiyon haline gelmiştir. KOL, NFT albüm projesinde üç farklı tür token hazırlamıştır. Hazırlanan bir token özel bir albüm paketidir. Diğer bir token sahiplerine müzik grubunun turnelerinde ömür boyu farkı ürün ve hizmetlere erişim imkanı sağlamaktadır. Fiziksel dünyada gerçekleşecek konserlerde, ön sıradaki koltuklar, VIP partilere katılım hakkı, özel sürücülü araç ile konsere erişim ve konser süresince özel hizmetler bu token içerisine yazılan akıllı kontrat ile erişime açılmaktadır. KOL'in bu NFT koleksiyonunun bir parçası olarak hazırlanan benzersiz biletlerin tanesi ortalama 100 bin Amerikan Doları bedel ile satılan bu tokenların gelirinden 500 bin Amerikan Doları üzerinde bir tutar Crew Nation fonuna bağışlanmıştır. 
KOL, bu NFT projesi ile Covid-19 nedeni ile çalışamayan müzisyenlere küresel olarak destek veren bu fon aracılığı ile destek sağlamıştır. Koleksiyonun üçüncü parçası olan NFT'ler, ayrıntılı görsel-işitsel sanata sahip 6 adet token olarak hazırlanmıştır. Üçüncü tip token ise sadece token sahiplerine özel ve yine KOL ve ekibi tarafından hazırlanmış görsel-işitsel sanat sunmaktadır. Ön izlemesi satış öncesinde yapılabilen bu tokenlar 95 Amerikan Doları ile 2.500 Amerikan Doları arasında fiyatlar ile satışa çıkartılmış ve tamamı satılmıştır.

KOL'un bu özel NFT projesi blokzincir teknolojisi kullanılarak tokenlara yazılımı yapılmış olan özel akıllı sözleşmeler ile müziğe değer katarak grubun hayranları ile etkileşimini artırma vaadini taşımaktadır. 'NFT Yourself' adı verilen bu çalışma dijital sanat yaklaşımı ile üretişmiş ve fiziksel sanat ile tokenlar üzerinden birleştirilmiş bir örnek çalışmadır. Fiziksel dünyadaki ürünlerin ve hizmetlerin tokenlaştırılması ile hayata geçmiş olan bu projede, hassas veriler farklı değerlerle ifade edilerek blokzincire kaydedilmiş ve değiştirilemez bir şekilde korunarak yönetilmesi sağlanmıştır. Hassas verilerin blokzincire aktarılarak şeffaf ve güvenilir bir şekilde, değiştirilmeden yönetilmesini sağlayan tokenizasyon, ağırlıklı olarak finans endüstrisinde başlamış olup, gayrimenkul ve ardından sanat alanında uygulamalar gözlemlenmeye başlamıştır. Fiziksel yada fiziksel olmayan varlıkların tokenize edilmesinin önemli sebepleri arasında aracıların ortadan kalkması gelmektedir. Hem maliyeti, hem de prosedürleri azaltan aracıların azalması yada tamamen aracısız işlem yapılabilmesi akıllı sözleşmeler aracılığı ile sağlanmaktadır. Blokzincir tabanlı varlık tokenizasyonunda akıllı sözleşmelerin kullanılması, sürecin büyük bir bölümünün otomasyonu için de verimlilik odaklı fayda sağlamaktadır. Aracıların azaltılması, aracıların maliyet yükünü ve tüm sürecin yönetiminde ihtiyaç duyulan çabaları ortadan kaldırmaktadır. KOL tarafından hayata geçirilen NFT projesinde, tokenların içerine yerleştirilen sanat eserleri ve konser bileti, VIP partilere katılım gibi hizmetler token sahibi tarafından hiçbir aracıya gerek kalmadan kullanılabilecektir. Kağıt, lojistik gereksinimler ve hatta kimlik ibrazı dahi gerektirmeden kilidi açılarak kullanılabilecek olan bu hizmetler, aracılara bağlı süreçlerin tamamen ortadan kalkmasını sağlamaktadır. Varlık ve değer yönetiminde yenilikçi bir bakış açısı sunan tokenizasyon, bu projede aracısız bir şekilde satışa sunulan ürünlere tokenlar aracılığı ile erişim imkanı da sunabilmektedir. Böylece, token sahipleri işlemleri daha hızlı ve daha düşük maliyet ile gerçekleştirebilecektir. KOL tarafından gerçekleştirilen sanat endüstrisindeki bu tokenizasyon projesi ile tokenlaştırılan ürünlerin orijinalliği ve sahipliği ile ilgili bilgiler güvenilir bir şekilde kayıt altına alınabilirken, token sahipleri için erişimi demokratikleştirme ve küreselleştirme bağlamında da oldukça yenilikçi bir çözüm sunulmaktadır. Varlıkların tokenizayonu ile sağlanan verimlilik konusunda şeffaflık önemli avantajlar sağlamaktadır. KOL projesinde de tokenların içerisindeki varlıkların tanımı ve sahiplik kaydı ile hak ve sorumlulukları pratik bir şekilde akıllı sözleşmelere kodlanmış veriler ile sağlanabilmektedir. Sonuç olarak, bu proje kapsamında tokenlar el değiştirdiğinde de hiçbir

sorun yaşanmadan şeffaf bir şekilde kayıtlara erişim güvenli ve hızlı bir şekilde sağlanabilecektir. Yatırımcılar yani token sahipleri, bu projeye ait ellerinde bulunan tokenlarını verimli ve kolay bir şekilde satarak herhangi bir zamanda projeden ayrılabilirler. Token sahiplerinin aracısız tokenlarını satma imkanı da olması satış sürecinin de hem verimli hem de küresel bir erişim ile yapılabilmesi imkanını sağlayabilmektedir.

Koleksiyon olarak hazırlanan NFT'ler KOL hayranlarının grubun müziklerine, biletlerine ve farklı bağlantılı birçok ürüne sahip olmasını sağlamasının yanı sıra, içeriğindeki ürün ve hizmetlerin ekonomik ömrünü de yönetebilmektedir. Temelde bir akıllı sözleşmeye dayalı programlanmış olan bu tokenlar, müzik endüstrisinde müziğin kendisinin dışındaki ekonomiye de dahil olmaktadır. NFT'ler ile yaratılan kripto ekonomi, bu tokenlar her el değiştirdiğinde kazanılan paranın bir kısmının yine bir platforma bağış amacı ile yollanabilmesine yada sanatçıya, sözleşmeye dahil olan başka bir kişiye otomatik transfer olabilmesine imkan vermektedir.

\section{BULGULAR VE TARTIŞMA}

Incelenen örnek vaka ve yapılan literatür taraması sonucu NFT'lerin müzik endüstrisinde, ve bağlantılı ürün ve hizmetlerde kullanımı incelenmiştir. NFT'lerin uygulanması ile ortaya çıkan yenilikler ve faydalar olmakla birlikte, daha geniş bir çerçevede avantajları ve dezavantajları da bulunmaktadır. Bu bölümde, NFT'lerin müzik endüstrisinde kullanımının olumlu etkileri ve potansiyel olumsuz etkilerine dair tartışma yapılacaktır. Tartışma NFT'lerin avantaj ve dezavantajları olarak 2 ana başlık altında yapılacaktır.

\subsection{NFT'lerin Avantajları}

\subsubsection{Benzersizlik Temsili ve Telif Hakkı Koruması}

NFT'ler belirli bir biricik, benzersiz varlığı (sanat eseri, belge, fiziki ürün vb.) temsil eder yada ona erişimi sağlar. Üçüncü bölümde de detaylı anlatılmış olan bu yapısal özelliklerinden dolayı NFT'ler diğer tüm blokzincir üzerinde üretilen kripto varlıklardan farklıdır. NFT’ler bu benzersiz varlığı yada değeri temsil ederken, üreticisi yada sahiplik durumu ile ilgili bilgileri de güvenilir ve şeffaf bir şekilde kayıt altına alırlar. Özellikle kolaylıkla çoğaltılabilen dijital sanat eserlerinde telif haklarının korunması veya izinsiz kullanımların önlenmesi en önemli sıkıntıların başında gelmektedir. 
Bir NFT’nin sahiplik bilgisi ve orijinal olup olmadığına dair bilgi kolaylıkla alınabilmektedir. Blokzincir protokolleri üzerinde zaman damgası ile kayıt altına alınan NFT ve içeriğindeki varlıkla ilgili tüm bilgiler şeffaf bir şekilde kontrol edilebilmektedir. Telif haklarının korunmasına da NFT'lerin üretimi esnasında programlanan akıllı sözleşme ile önemli bir katma değer getirilebilmektedir. İlgili üreticiye ait bir NFT her satıldığında üretici programlanmış şartlara bağlı telif hakkını da satış geliri üzerinden alabilmektedir.

\subsubsection{Yeni İş Modellerine Imkan Vermesi}

NFT'ler varolan blokzincir sistemlerini farklılaştırarak yeni örnek vakalar ortaya çıkartabilmektedir. Örnek vakalardan en önemlilerinden birisi dijital varlıkların otantik yapısı, ve benzersizliği garanti altına alınarak tokenize edilmesidir. NFT'ler özellikle dijital sanat eserleri için kullanışlı ve yenilikçi bir yönetişim yaklaşımı getirmektedir. (Griffin, 2018) KOL örneğinde NFT sahipliği özel tasarlanmış bir konser biletini açabilmektedir. Token haline getirilmiş olan bu bilet benzersizliğini koruyabilmektedir. Yani herhangi bir konser bileti yada yine KOL grubuna ait başka bir konser bileti ile aynı değildir. Benzersizliği koruyarak yegane fiziksel ve dijital varlıkların tokenlaştırılmasına imkan veren bu kripto para çeşidi blokzincir teknolojisini altyapı olarak kullanan yeni iş modelleri gelişmesine imkan verebilmektedir. NFT'ler bu benzersiz varlığı yada değeri temsil ederken, onu programlanabilir hale getirmektedir. Varlığın sahip olduğu değere, akıllı sözleşme ile program olarak ekleme yapılarak ilave değer kazandırılabilmektedir. KOL'in NFT uygulamasında sanat eseri olan müzik yani grubun albümünde sunduğu müzik eserlerine NFT hazırlanırken ilave değer eklenmesi mümkün olmuştur. Proje kapsamında üretilen NFT'ler içeriğindeki müzik eserleri gibi benzersiz ürün ve hizmetlere erişimi de sağlayacak şekilde programlanmıştır. Yani token sahiplerinin bu proje kapsamındaki müzik eserine erişiminin yanı sıra grubun konserlerinde kendilerine ait yere erişim yada müzik grubunun yaratıcı ekibi tarafından sadece o NFT'ye sahip olanlar için üretilmiş özel dijital tasarımlara erişim imkanı sağlanmaktadır. Benzersiz olmayan varlıklar ayrıca NFT'ye eklenerek yapılacak farklılaştırma ile yine benzersiz yeni bir değer ortaya çıkarılabilmektedir.

\subsubsection{Fiziksel ve Dijital Dünya Entegrasyonu}

Fiziksel dünya varlıklarının, benzersizliğini koruyarak dijital dünyaya entegre edilmesi NFT'ler ile sağlanabilmektedir. NFT'ler ile fiziksel dünyaya ait hizmetler tokenize edilerek dijital dünyada temsil edilebilmekte ve yönetilebilmektedir. (Regner et al., 2019) Bu temsilde blokzincir teknolojisi altyapısı ile sağlanan şeffaflık boyutu, takip edilebilirliği de beraberinde getirdiği için, fiziksel dünyadaki benzer uygulamalardan farklılaşmaktadır. Özellikle aracılara olan bağımlılığı ortadan kaldırmakla birlikte, NFT'ler dijital dünyaya entegre edilmiş fiziksel varlıkların güvenli ve daha düşük maliyetlerle verimli bir şekilde aracısız transfer yada satışını sağlamaktadır. Bugüne kadar NFT uygulamaları ile lisanslar, lüks tüketim ürünleri ve hatta otomobillerin tokenize edilmesi üzerine çalışmalar yapılmıştır. (Griffin, 2018) İncelenen örnek NFT projesinde de görüldüğü üzere, KOL grubuna ait konser biletlerini temsil eden NFT'ler bir bilet satış aracı kurumuna ihtiyaç olmadan güvenli, hızlı bir şekilde farklı bir kullanıcıya direkt satılabilecektir.

\subsubsection{Güvenlik}

NFT'lerin güvenlik konusundaki avantajları iki ayrı boyutta tartışılabilir. İlk güvenlik avantajı, NFT'lerin blokzincir üzerinde üretilmelerinden kaynaklı, değiştirilemez bir şekilde kayıt altına alınabilmeleri ile ilgilidir. Blokzincir, yapılan her işlem bilgisinin ağdaki işlemleri çözen, kontrol eden ve onaylayan düğüm adı verilen katılımcılar tarafından kaydedildiği ve paylaşıldığı dağıtık bir veri yönetim defteri yapısıdır. (Nakamoto,2008) Dağıtık bir veritabanı, kriptografik algoritmalar ve merkeziyetsiz bir kontrol, mutabakat ve onay mekanizmasından oluşan (Zhao, Fan, Yan, 2016) blokzincirin en önemli özelliği, ağ katılımcıları tarafından gerçekleşen hesaplamalar ile güvenilir bir şekilde işlemlerin gerçekleşmesidir. Bu özelliği ile blokzincir kullanıcılar için merkezi olmayan dağıtık veri yapısı sayesinde güvenliğin temelini oluşturmaktadır. (Narayanan, 2017) Bu teknoloji ile değiştirilemez bir şekilde kayıt altına alınan NFT'lerin içeriğindeki varlıklar ile orijinallik ve sahiplik bilgisi gibi veriler yüksek bir güvenliğe sahiptir.

Diğer bir güvenlik boyutu, potansiyel siber saldırıların ortaya çıkartacağı tehditlerdir. Bugüne kadar rapor edilmiş hiçbir NFT saldırısı olmamıştır. (Gilbert, 2021) Siber saldırılara karşı bugüne kadar risk altında kalmamış olan NFT'ler açısından güvenlik tartışması, saklama hizmeti sunan kripto varlık cüzdanlarının güvenlik özellikleri üzerinden yapılmaktadır. Bir NFT sahipliği için gerekli koşullardan biri kripto varlık saklama cüzdanına sahip olmaktır. Ve bu cüzdanın kendi güvenlik unsurları ötesinde kullanıcı tarafından dikkate alınması gereken güvenlik tedbirleri de bulunmaktadır. Bu bağlamda hem kripto varlık cüzdanının güvenlik kapasitesi hem de NFT sahibinin dijital okuryazarlık seviyesi ve yetkinlikleri NFT’lerin güvenlik limitleri üzerinde etkili olmaktadır.

\subsection{NFT'lerin Dezavantajları}

\subsubsection{Blokzincir Altyapısına Bağımlılık}

NFT'ler içeriğindeki varlık yada erişim sağladığı veriden bağımsız, yazılımsal bir kod olarak düşünüldüğünde, yazılımın bağlı olduğu blokzincir protokolüne bağımlılıklarının riskini taşımaktadır. Benzer şekilde NFT'lerin üzerinde üretildiği blokzincir protokolünün özelliklerinin el verdiği kadar ölçeklenebilir olması da blokzincir altyapısına bağlı dezavantajlardan birisidir. 
NFT'lerle ilgili yine üzerinde geliştirildiği blokzincir bağlamında yapılabilecek bir tartışma da çevre boyutundaki olumsuz etkileridir. Blokzincir protokolünün çalışma yöntemine bağlı olarak değişkenlik göstermekle birlikte, NFT'lerin üzerinde geliştirildiği ağın çalışması için harcanan enerji ve elektrik tüketimi çevreye olumsuz zarar vermektedir. Önceki bölümde değinildiği üzere bugün en çok NFT geliştirilen blokzincir protokolü olan Ethereum iş ispatı yöntemi ile çalışmaktadır. Ve iş ispatı yöntemi ile çalışan blokzincir protokollerinde madencilik yüksek maliyetlidir ve ciddi seviyede elektrik harcarken aynı zamanda yüksek mikarda atık üretir. (Holden, Linnerud, Banister, 2017) Tek bir Bitcoin transfer işlemi için harcanan enerji tüketimi üzerinden tahminleme yöntemi ile küresel ölçekte gerçekleşecek işlemleri hesaplandığında, bu enerji miktarı dünya genelinde ısının $2{ }^{\circ} \mathrm{C}$ derece yükselmesine neden olacaktır. (Diesendorf, 2020) Farklı yöntemlerle çalışan blokzincir protokolleri daha az enerji harcamakta ve madencilik firmaları yenilenebilir enerji kaynaklarına yönelmektedirler. Daha düşük maliyetle gerçekleşiyor olsa da tartışmanın tüm teknoloji ürünlerinde olduğu gibi enerji tüketiminin insanlık için sağladığı faydalar odağında yapılması daha sağlıklı olacaktır. Bazen teknoloji insanlık için o kadar yenilikçi ve faydalıdır ki, olumsuz etkileri ile olumlu faydaları dikkatle tartışılmalıdır. Bununla beraber, blokzincir teknolojisinin enerji tüketimini azaltacak ve doğaya zarar vermeyecek hale getirecek şekilde yenilenebilir enerji kaynaklarının madencilikte kullanımını artıracak çalışmalar küresel ölçekte devam etmektedir. Özellikle halka arz olan temiz enerji kullanan madencilik firmaları bu alanda küresel vizyonu değiştirmekte ve Idierlik etmektedir.

\subsubsection{Gizlilik}

NFT'ler açık blokzincir protokolleri üzerinde geliştirildiğinde, blozincirin temel özelliklerinden olan şeffaflık konusu sağladığı avantajların yanı sıra dezavantajları olan bir konudur. Blokzincir üzerindeki tüm işlemler gibi, NFT ile ilgili tüm işlemler, transfer bilgileri, fiyat bilgileri gibi veriler açık ve şeffaf bir şekilde takip edilebilecektir. Sanatçıların eserlerinin fiyatı yada sahipliği ile ilgili bilgilerin şeffaf olması sanatçı yada koleksiyoner tarafından avantajları kadar dezavantajlarına göre de eğerlendirilmelidir. Birden fazla araştırmacı, şeffaflığın ve açık erişiminin önemli bir özellik olduğu açık blokzincirlerde takma adlı verilerden dahi anlam çıkarmak mümkün olduğu için, gizliliğin garanti edilmediğini öne sürmektedir. (Tschorsch, Scheuermann, 2016) Yani anonim kimlikler ve hesaplarla yapılan işlemler dahi, farklı işlem bilgileri ile linklenerek kimlikler açığa çıkartılabilmektedir. Tam anlamı ile üretici yada alım satım işlemine dahil olan kişiler ile ilgili kimliklerin anonim kalması konusunda bir netlik bulunmamaktadır.

\subsubsection{Kullanıcı Deneyimi}

Sanat tüketicileri için NFT olarak eserlere erişim küresel olarak ve aracısız bir şekilde mümkün olabilmektedir. Sanatçıların herkes için sanat üretme vizyonuna parallel avantaj sağlayan erişim imkanı, dijtal okuryazarlık ve kripto okuryazarlığı engeli bağlamında kullanıc deneyimini zorlaştırabilmektedir. Blokzincir teknolojisi hakkında bilgi düzeyi ile kripto varlık cüzdanı sahipliği ve kullanım bilgi düzeyine bağlı olarak NFT varlıklara erişim de zorluk yaratabilmektedir. Oldukça teknik bir dili olan blokzincir ve kripto paralar, hem terminoloji hem de kullanım olarak henüz yaygınlaşmamıştır. Sadece tüketici tarafında olmamakla birlikte, üretici paydaşlar nezdinde de eserlerini ve değerleri blokzincire aktararak NFT olarak satışa sunmaları ve devam eden süreçte NFT ile vaadedilen hizmet yada ürünlere erişim sağlanması yazılım ve takip gerektiren süreçlerdir. Üretimde kullanılabilecek Ethereum, Avalanche gibi farklı protokoller ve satış tarafında kullanılabilecek Nifty Gateway, OpenSea gibi platformlar olsa da, bunlara erişim ve planlama süreçleri de sanat üreticileri için aşılması gereken zorluklar arasındadır. Sanat eseri ve sunulan NFT'deki diğer ürünlerin fiyatının yanısıra altyapıdaki blokzincirin transfer maliyetleri de kullanıcı deneyiminde olumsuz etki yaratabilmektedir. Bu maliyetin ödendiği kripto para cinsindeki fiyat hareketliliği ve değişkenliği de satın alma esnasında kullanıcı deneyimini maliyet odaklı olumsuz etkileyebilmektedir. Tüketici tarafında bu işlem maliyeti satın alınacak eserin maliyet hesaplamasını da etkilemektedir.

Teknolojinin kendisininin başlıbaşına bir deneyim olduğu yaklaşımı (Lemon, Verhoef, 2016) ile NFT uygulamaları değerlendirildiğinde, kullanıcı deneyimine getirdiği avantajlar ayrıca değerlendirilmelidir. NFT olarak satın alınan sanat eserinin erişim, saklama ve yeniden satma süreçlerinde teknolojinin sunduğu süreç ile sağladığı avantajlar NFT'leri konvasiyonel sanat eserlerine göre avantajlı duruma getirebilmektedir. McCarthy ve Wright (2004:194) tarafından öne sürülen ve deneyim olarak teknoloji nin değerlendirildiği çalışmalarda da vurgulandığı şekilde, digital deneyimde düşünsel olarak büyülenme ile gelen deneyim de göz ardı edilmemeliddir. Sanat yerlerini potansiyel, özgürlük, yenilik ve sürprizlerle dolu açık bir yer haline getiren blokzincir teknolojisi ve NFT'ler, düşünsel boyutta müşteri deneyimini olumlu yönde etkileme potansiyeline de sahiptir.

\subsubsection{Yasal Boyut}

NFT olarak satın alınan sanat eserinin sahipliği ve orjinalliği blokzincir sistemi ile garanti altına alınabilmektedir. Fakat kripto varlıklarla ilgili henüz birçok ülkede net olmayan yasal boyut, kullanıcı deneyimi ve sahiplik bağlamında risk unsurlarındandır. Bu zeminde hala tartışmalar ve bir çok ülkede yasa koyucu tarafında bir regülasyon üzerine çalışmalar devam etmektedir. Bu konuda hukuki bir netlik olmaması hem üretici hem de tüketici tarafında NFT sahipliği, satın alma, ve satış yapma bağlamında dezavantajlardan biri haline gelmektedir. 


\section{SONUÇ}

Blokzincir teknolojisi nispeten yeni bir teknoloji olmasına rağmen hızla artan kullanım alanları bulmaktadır. Blokzincir teknolojisi üzerinde geliştirilen kripto varlıklardan olan NFT'ler, blokzincir 2.0 olarak anılan geçişin başlamasını tetikleyen akıllı kontratların kullanılması ile birlikte, 2015 yılı itibarı ile gerçek dünya kullanım alanları bulmaya başlamıştır. NFT'ler varolan diğer kripto varlıklardan farklı olarak para tutmak yerine benzersiz olan bir varlığı temsil edebilmetedir. Bu özelliği ile NFT'ler son yıllarda özellikle oyun ve sanat sektörlerinde yaygınlaşmaya başlamıştır. NFT'ler sahip olduğu benzersizlik temsili ve blokzincir üzerinde şeffaf, değiştirilemez kayıt tutulabilmesine imkan veren teknik özellikleri sayesinde uygulama bulduğu sektörlerde önemli dinamikleri dönüştürmeye adaydır. Illk kez CryptoKitties ile kullanılmaya başlayan ve 2020 yılı itibarı ile sanat sektöründe çok hızlı bir büyüme ve yaygınlaşma yakalayan NFT'lerin toplam pazar değeri de hızla büyümektedir. NFT'lerin sanat sektöründe müzik endüstrisinde kullanımı ile ilgili ilk ve küresel çaplı hayata geçen uygulama 2021 yılında gerçekleşmiştir. Bu uygulama örnek olarak incelenerek ikinci kaynak taramasından elde edilen bilgiler ile yapılan bu araştırmada, NFT uygulamalarının geleneksel uygulamalara göre avantaj ve dezavantajları tartışımıştır.

Müzik endüstrisinde NFT uygulamalarının eserlerin benzersizlik ispatı, telif hakları, yeni iş modelleri, dijital entegrasyon, ve güvenlik alanlarında avantajları bulunmaktadır. NFT'ler belirli bir biricik, benzersiz varlığı yada değeri temsil ederken, üreticisi yada sahiplik durumu ile ilgili bilgileri de güvenilir ve şeffaf bir şekilde kayıt altına alırlar. Kolaylıkla çoğaltılabilen dijital sanat eserlerinde telif haklarının korunması ya da izinsiz kullanımların önlenmesi blokzincir üzerinde alınan değiştirilemez ve şeffaf kayıtlar ve NFT'lerin üretimi esnasında programlanan akıllı sözleşmeler ile sağlanarak önemli bir avantaj sağlanmaktadır. NFT'ler bir benzersiz varlığı yada değeri temsil ederken, onu programlanabilir hale getirmektedir. Token haline getirilerek fiziksel dünyadan dijital dünyaya güvenilir bir şekilde NFT olarak aktarılabilen eserler blokzincir teknolojisini altyapı olarak kullanan yeni iş modellerinin gelişmesine imkan verebilmektedir. Tüm bunlara ilave olarak NFT'lerin güvenlik konusunda blokzincir üzerinde değiştirilemez bir şekilde kayıt altına alınmaları ve siber saldırılara karşı bugüne kadar risk altında kalmamış olmaları da önemli bir avantajdır. Henüz yeni yeni uygulama alanları bulmaya başlayan NFT'ler, mevcut geliştirme ve kullanım süreçlerinde içeriğindeki varlık yada erişim sağladığı veriden bağımsız yazılımsal bir kod olarak düşünüldüğünde, yazılımın bağıı olduğu blokzincir protokolüne bağımlııklarının riskini taşımaktadır. Blokzincirler arasında birlikte çalışabilirlik entegrasyonlarının gerçekleşemesi ile gelecekte ortadan kalkma potansiyeli olan bu dezavantaj, bugün için bağımlılığın yanı sıra ölçeklenebilirlik sorununu da getirmektedir. NFT'lerle ilgili yine üzerinde geliştirildiği blokzincir bağlamında yapılabilecek bir tartışma olan çevre boyutundaki olumsuz etkileri de blokzincir protokolünün çalışma yöntemine bağlı olarak değişkenlik göstermekle birlikte, bu tartışmanın tüm teknoloji ürünlerinde olduğu gibi enerji tüketiminin insanlık için sağladığı faydalar odağında yapılması daha sağlıklı olacaktır.

Sadece tüketici tarafında olmamakla birlikte, üretici paydaşlar nezdinde de eserlerini ve değerleri blokzincire aktararak NFT olarak satışa sunmaları ve devam eden süreçte NFT ile vaadedilen hizmet yada ürünlere erişim sağlanması yazılım ve takip gerektiren süreçlerdir. Oldukça teknik bir dili olan blokzincir ve kripto paralar, hem terminoloji hem de kullanım olarak henüz yaygınlaşmamıştır. Bu sebepten ötürü, yeni bir teknoloj olan blokzincir teknolojisi alanında teknolojik okuryazarlığı düşük olan üretici ve tüketicilerin NFT kullanımı ile ilgili zorluk yaşaması, NFT'lerin yaygınlaşmasının önündeki engellerden biri olmakla beraber, teknolojinin kişilerin sürece dahil olarak tasarımın bir parçası olmasına imkan verebiliyor olması yaklaşımı ile NFT olarak satın alınan sanat eserinin erişim, saklama ve yeniden satma süreçlerinde teknolojinin sunduğu süreç ile sağladığı avantajlar NFT'leri konvasiyonel sanat eserlerine göre avantajlı duruma getirebilmektedir. McCarthy ve Wright (2004:194) tarafından öne sürülen ve deneyim olarak teknolojinin değerlendirildiği çalışmalarda da vurgulandığı şekilde, dijital deneyimde düşünsel olarak büyülenme ile gelen deneyim de göz ardı edilmemeliddir. Sanat yerlerini potansiyel, özgürlük, yenilik ve sürprizlerle dolu açık bir yer haline getiren blokzincir teknolojisi ve NFT'ler, düşünsel boyutta müşteri deneyimini olumlu yönde etkileme potansiyeline de sahiptir.

Sanat ekosisteminin iç dengeleri göz önünde bulundurulduğunda, NFT'ye ait tüm bilgilerin şefaf bir biçimde erişilebilir olmasının da beraberinde getirdiği avantajlar stratejik dengeler üzerinde etkili olabilecek dezavantajlara dönüşme riskini taşımaktadır. Özellikle sahiplik ve fiyat bilgisi gibi konularda her ne kadar üretici yada alım satım işlemine dahil olan kişiler ile ilgili kimliklerin anonim kalması konusunda bir netlik bulunmamakta ise de kişisel tercihlere bağlı yönetilebilecek şekilde hazırlanan akıllı sözleşmeler bu konuda çözüm sunabilir nitelikte olacaktır. Kişisel verilerin gizliliği ile ilgili yasal boyuttaki tartışmaların yanı sıra, blokzincir teknolojisinin ürünlerinden olan kripto paraların kullanımı ile ilgili yasal mevzuat ve kripto varlıkların kanuni nitelikleri de henüz dünya genelinde tartışılmakta olan bir konudur. Ülkelere ve hatta bölgelere göre farklı uygulama önerileri tartışılan yasal mevzuat kapsamındaki belirsizlik, NFT uyguamalarının sanat endüstrisindeki kullanımının yaygınlaşması önündeki önemli engellerden biridir. NFT olarak satın alınan sanat eserinin sahipliği ve orjinalliği blokzincir sistemi ile garanti altına alınabilmektedir. Fakat kripto varlıklarla ilgili henüz birçok ülkede net olmayan yasal boyut, kullanıcı deneyimi ve sahiplik bağlamında risk unsurlarındandır. Bu zeminde hala tartışmalar ve bir çok ülkede yasa koyucu tarafında bir regülasyon üzerine çalışmalar devam etmektedir. Bu konuda hukuki bir netlik olmaması hem üretici hem de tüketici tarafında NFT sahipliği, satın alma, ve satış yapma bağlamında dezavantajlardan biri haline gelmektedir. 
NFT'lerin uygulanması ile ortaya çıkan yenilikler ve faydalar olmakla birlikte, bu uygulamaların hayata geçirilmesinin önünde engeller de bulunmaktadır. Müzik endüstrisinde önemli avantajlar sağlama potansiyeli olan NFT'lerin yaygınlaşmasının üreteceği sonuçlar takip edilerek araştırmalarla desteklenmeli ve akademik alanyazına katkı sağlanmalıdır.

\section{KAYNAKÇA}

Beck, R. Stenum Czepluch, J. Lollike, N. S. Malone. (2016). Blockchain - the gateway to trust-free cryptographic transactions. Twenty-Fourth European Conference on Information Systems (ECIS), İstanbul, Turkey, 2016. Springer Publishing Company.

Cohen, B. Amorós, J.E. Lundyd, L. (2017). The generative potential of emerging technology to support startups and new ecosystems. Business Horizons, 60(6): 741-745.

Coin Market Cap., (2020). NFT Collections Listed By 7 Day Sales Volume. Retrieved from https://coinmarketcap.com/nft/collections/ 11.06.2021

Diesendorf, M., (2000). Sustainability and sustainable development. Sustainability: The corporate challenge of the 21st century, Sydney: Allen\& Unwin, 2, 19-37.

ERC721, (2020). A Class of Unique Tokens. Retrieved from http://erc721.org/ 07.05.2021

Ethereum, (2021). Introduction to Smart Contracts. Retrieved from https://ethereum.org/en/developers/docs/smart-contracts/ 07.05.2021

Gilbert, T., (2021). For sale: an overview of non-fungible tokens (NFTs) and IP. Retrieved from https://ipwhiteboard.com.au/for-sale-this-articlean-overview-of-non-fungible-tokens-nfts-and-ip/

Glaser, F., (2017). Pervasive decentralisation of digital infrastructures: a framework for blockchain enabled system and use case analysis. Proceedings of the 50th Hawaii International Conference on System Sciences. 1543-1552. DOI: 10.24251/HICSS.2017.186.

Griffin, J., (2018). Software licences as non-fungible tokens. Retrieved from https://medium.com/collabsio/software-licences-as-non-fungibletokens-1f0635913e41

Halpin, H. Piekarska, M., (2017). Introduction to security and privacy on the blockchain. IEEE, Security and Privacy Workshops, IEEE European Symposium, 1-3.

Holden, E. Linnerud, K. Banister, D., (2017). The imperatives of sustainable development. Sustainable Development, 25(3), 213-226 DOI:10.1002/sd.1647

lansiti, M. Lakhani, R. K., (2017). The truth about blockchain. Harvard Business Review, January-February, 1-17.

Lemon, K. Verhoef, P. C., (2016). Understanding customer experience throughout the customer journey. Journal of Marketing, 80 (6), $69-96$.

Majchrzak, A. Markus, M. L., (2014). Technology affordances and constraints in management information sytems. Encyclopedia of Management Theory, Thousand Oaks: Sage Publications.

Martine, G. Alves, J.E.D., (2015). Economy, society and environment in the 21st century: three pillars or trilemma of sustainability? Brazilian Journal of Population Studies, 32(3), 433-460. DOI:10.1590/S0102-3098201500000027

Mccarthy, J. Wright, P., (2004). Technology as Experience. The MIT Press.

McLuhan, M., (1964). Understanding Media: The Extensions of Man, The MIT Press.

Nakamoto, S., (2008). Bitcoin: a peer-to-peer electronic cash system. Retrieved from https://bitcoin.org/bitcoin.pdf.

Narayanan, A. Clark, J., (2017). Bitcoin's academic pedigree. Communications of the ACM, 60(12), 36-45. DOI:10.1145/3132259

Regner, F. Schweiser, A. \& Urbach, N., (2019). NFTs in practice - non-fungible tokens as core component of a blockchain-based event ticketing application. 40th International Conference on Information Systems (ICIS 2019). Munich, Germany, 8-15.

Tapscott, D. Tapscott, A., (2016). The impact of the blockchain goes beyond financial services. Harvard Business Review, 10, 7-18.

The Verge., (2021, May 17) NFT Explainer: What is blockchain crypto art? Retrieved from https://www.theverge.com/22310188/nft-explainerwhat-is-blockchain-crypto-art-faq

The New York Times, (2018, May 18). Cryptokitty auction. Retrieved from https://www.nytimes.com/2018/05/18/style/cryptokitty-auction.html

Tschorsch, F. Scheuermann, B., (2016). Bitcoin and beyond: a technical survey on decentralized digital currencies. IEEE Communication Survey Tutorial, 18, 2084-2123. DOI:10.1109/COMST.2016.2535718

Waybackmachine, (2014, February 8). Ethereum. Retrieved from https://web.archive.org/web/20140208030136/http://www.ethereum.org/ 06.05.2021 
Yeşilorman, M. Koç, F., (2014). Bilgi toplumunun teknolojik temelleri üzerine eleştirel bir bakış. Fırat Üniversitesi Sosyal Bilimler Dergisi, 24(1), 117-133.

Zhao, J. Fan, L. S. Yan, J., (2016). Overview of business innovations and research opportunities in blockchain and introduction to the special issue. Finance Innovation, 2, 28-38.

Zheng, Z. Xie, S. Dai, H. Chen, X. Wang, H., (2017). An overview of blockchain technology: architecture, consensus, and future trends. Big Data Congress, 85-90. 